\title{
Deliverance of the Adolescent Friendly Health Service Standards by Nurses in Otjozondjupa Region of Namibia
}

\author{
Marry Muyenga ${ }^{1}$, Kristofina Amakali ${ }^{1} \&$ Wilma Wilkinson ${ }^{1}$ \\ ${ }^{1}$ School of Nursing; Faculty of Health Sciences; University of Namibia, Namibia \\ Correspondence: Kristofina Amakali, School of Nursing, Faculty of Health Sciences, University of Namibia, \\ Private Bag 13301, Windhoek, Namibia. Tel: 264-61-206-3297. E-mail: kamakali@unam.na
}

Received: April 19, 2017 Accepted: May 26, 2017 Online Published: August 28, 2017

doi:10.5539/gjhs.v9n10p51 URL: https://doi.org/10.5539/gjhs.v9n10p51

\begin{abstract}
Despite the implementation of the national standards for Adolescent Friendly Health Services (AFHS) towards the prevention among others teenage pregnancy the, problem continues to rise across the regions of Namibia.

This article presents the findings of a quantitative, cross-sectional, descriptive, analytical study regarding the implementation of the components on Adolescent Friendly Health Care Providers and the Adolescent Friendly Environment of the Adolescent Friendly Health Services standards by nurses in Otjozondjupa Region of Namibia.

Quantitative data were collected from 12 registered nurse midwives and 23 enrolled nurse-midwives who implement the AFHS at the health care facilities (through structured self-interview questionnaire) and 18 health care facilities that implement the AFHS in Otjozondjupa Region (through checklist) for triangulation of the data. The data were analysed using the SPSS Version 16 data base. Descriptive and inferential statistics were performed on selected variables to determine the relationship of variables.

The findings indicated that only $30 \%$ of the registered nurse-midwives compared to $75 \%$ of the enrolled nurses who implement the AFHS were formally trained in adolescent reproductive and sexual health issues. The findings further indicated that although $75 \%$ and $87 \%$ of the respective categories of nurse respondents indicated that they conduct school outreach activities, the initiative seems not being implemented effectively as can be inferred from only $14 \%$ of the registered nurse who indicated that they do conduct health education at schools. In the same vein, $90 \%$ of the health facilities had no spaces that were designated for the adolescent health services. Therefore, the recommendations were made in respect of the implementation of these two components of the AFHS standards at the health care facilities in the region.
\end{abstract}

Keywords: health service standards, otjozondjupa region, Namibia

\section{Introduction}

In 2011, the World Health Organization [WHO] recommended the implementation of the Adolescent Friendly Health Services (AFHS) standards for sensitization of the adolescent on reproductive health, including the prevention of teenage pregnancy. The goal of the AFHS standard is to provide comprehensive equitable health services for the adolescents. The Adolescent Friendly Health Services standards outline six components of the services for the adolescents, to be implemented through a multi-sectoral approach to ensure that the services are available and accessible to the adolescents. These six components include: Adolescent Friendly Health Service Providers, Adolescent Friendly Health Procedures, Adolescent Friendly Health Environment, Adolescent Active Participation, Community Support and Participation, as well as Networking and Collaboration (Ministry of Health and Social Services [MoHSS], 2011).

The component on the Adolescent Friendly Health Service Providers advocates for the provision of services to the adolescents by health care providers who are understanding, easy to relate to, non-judgmental and trustworthy, because these characteristics encourages the adolescents to make use of the service (WHO, 2003, WHO, 2012). By the implication, the intended goals of the Adolescent Friendly Health Services Standards in Namibia would have been effective only, if the implementers provide the services in an adolescent friendly approach.

In addition, the standards emphasize that for effective implementation of adolescent friendly procedures, each 
health facility should display an "adolescent friendly environment", which provide convenient, accessible and attractive services to most adolescents offered in the space that is designated to the adolescents' services only, in order to minimize the risk for stigma (UNCEF \& MoHSS, 2008).

The last component of the standards advocates for the scaling up of the implementation of the Adolescent Friendly Health Services through a multi-sectoral approach by linking the AFHS service provision with other local stake holders (WHO, 2002) in realization that multi-sectoral approach is necessary for the successful delivery of a comprehensive adolescent health services.

Based on the WHO' recommendations, the Namibian government adopted and implemented the AFHS standards in 2011 in line with the National Policy on Reproductive Health. The roles of the participatory stakeholders in this initiatives are distinctively outlined (MoHSS, 2011).

Therefore, in 2011, upon adaptation of the AFHS standards, the Namibian Ministry of Health and Social Services implemented the components of Adolescent Feriendly Health Care Providers and Adolescent Friendly Environment in all 14 regions of service deliverance in line with the National Policy on Reproductive Health (MoHSS, 2011). These components are mainly implemented by nurses at the primary health care level of the health services.

Despite the implementation of the AFGS standards, the average rate of teenage pregnancy in Otjozondjupa region before and after the implementation of the AFHS standards showed no significant difference as it only changed from 5.9\% in 2008 to 5.3\% in 2012 respectively (MoHSS, 2012). Two questions therefore remain to be answered, vis a vis: whether the nurses at the health care facilities in Otjozondjupa region do implement the Adolescent Friendly Health Services standards effectively and whether the health care facilities in the Otjozondjupa region are adolescent friendly services oriented. It was therefore important to assess the implementation of these two components as they directly influence adolescents' intention to seek for health services. This article presents the study findings on the implementation of adolescent friendly health service providers, and the adolescent friendly health environment at the health facilities in Otjozondjupa region of Namibia.

\section{Goal and Objectives}

The goal for the original study was to assess the implementation of the Adolescent Friendly Health Services by nurses at health care facilities in Otjozondjupa region.

The specific objectives of the study were partially to describe the implementation of the components on adolescent friendly health care providers and the evidence for the implementation of the adolescent friendly environment component of the AFHS at the health facilities in Otjozondjupa region.

\section{Research Design and Methods}

\subsection{Research Design}

A quantitative, cross-sectional descriptive, analytical study was conducted (Brink, van Rensburg, van der Walt 2012, Babbie E, Mouton J (2010).

\subsection{Study Population}

The study was conducted among two (2) respective populations of 38 nurses [14 registered nurse- midwives and 24 enrolled nurse-midwives] who implement the AFHS at the health care facilities, and 19 health care facilities where the AFHS is being implemented in Otjozondjupa region.

\subsection{Inclusion and Exclusion Criteria}

Only nurses who provided services in 19 health care facilities in Otjozondjupa regions were included in the study. All categories of nurses [registered nurse-midwives and enrolled nurse-midwives] in the respective health care facilities were included in the study. Similarly, only the 16 clinics and 3 health centres in Otjozondjupa regions were included in the study. Nurses and health care facilities outside the Otjozondjupa regions were excluded from the study.

\subsection{Sampling and Sample Size}

All 38 nurses and 19 health care facilities were included in the study, to ensure validity of the data. Out of 38 nurses, 35 participated in the study. Out of the 19 health facilities, 18 participated in the study.

\subsection{Data Collection Tool}

A semi-structured questionnaire was used to collect the data about adolescent friendly health services provider, while a checklist was used to collect the data on evidences of adolescent friendly environment in the health care 
facilities.

\subsection{Data Collection Methods}

The data on the component: Adolescent friendly health care providers were collected from all 35 nurses. The study participants completed the self-administered questionnaires under direct supervision of the researcher. The data on the Adolescent friendly health environment component were collected at the 18 health care facilities [ 3 health centres and 15 clinics] of all 19 health facilities that implement the AFHS in Otjozondjupa region. A checklist on evidences of the implementation of adolescent friendly health services was completed by the researchers. Completed questionnaires and checklists were numbered and sealed for validation by the researchers before analysis.

\subsection{Data Analysis}

Descriptive statistics were performed and categorical data was presented in forms of frequencies and percentages. Inferential statistics were performed on selected variables to describe and determine the relationship of variables using SPSS Version 16 data base (De Vos, Strydom, Fouche \& Delport, 2011; Joubert \& Ehrlich, 2014)

\section{Ethical Implications}

Ethical principles of justice, autonomy, protection of participants from harm and beneficence was observed. The study was approved by both the Ethical, Research and Publication unit of the University of Namibia and the Research and Ethical Committee of the Ministry of Health and Social Services. Nurses were the justifiable sources of the data needed: as the implementers, they were well-placed to provide the information about the implementation of the two components of the Adolescent Friendly Health Services initiative. Written informed consent was obtained from the nurse participants after the prospect participants were informed about the purposes of the study and the methods of feedback of the research outcomes. Participation was voluntary. Confidentiality was maintained as the researcher was the only one who had access to the data. Anonymity was maintained. Participants were identified by codes and not by their names (Parahoo, 2006 \& Streubert Speziale \& Carpenter, 2007).

The principle of beneficence was observed as the findings of the study would inform necessary improvement in deliverance of Adolescent Friendly Health Friendly Services in the region (Joubert \& Ehrlich, 2014).

\section{Rusults}

In this section, the findings of on the data about the two components that were assessed are presented.

\subsection{Sample Achievement}

The actual study sample yielded $34.3 \%, 65.6 \%$ and $95 \%$ of the registered nurses-midwives, enrolled nurses-midwives and health facilities respectively as displayed in Table 1.

Table 1. Data collection sample achievement

\begin{tabular}{llll}
\hline Study Data Collection Source & Study Estimated sample & Actual Achieved Sample & Estimated Percentage Yield \\
\hline Registered Nurses & 14 & 12 & $34.3 \%$ \\
Enrolled Nurses & 24 & 23 & $65.7 \%$ \\
Health Facilities & 19 & 18 & $95 \%$ \\
\hline
\end{tabular}

\subsection{Adolescent Friendly Health Services Providers}

Out of the 35 nurses in the study, the majority $(71,4 \%)$ were female. There were more $(65.7 \%)$ enrolled nurses than registered nurses (34.3\%) who participated in the study. More than half (54\%) of the nurses have been in service for 6 to 10 years. The other variable that was analysed was the characteristics of providers per health facility, as displayed in Table 2 . 
Table 2. Types of health facilities and the characteristics for nurse providers for the adolescent friendly health service per health facility

\begin{tabular}{|c|c|c|c|c|c|c|}
\hline \multirow[b]{2}{*}{ Variable } & & \multicolumn{5}{|l|}{ Facilities } \\
\hline & & Grootfontein & Okahandja & Okakarara & Otjiwarongo & Total \\
\hline \multirow{2}{*}{$\begin{array}{l}\text { Type of Health } \\
\text { Facility }\end{array}$} & Clinic & $5(83.3 \%)$ & $2(100.0 \%)$ & $6(100.0 \%)$ & $2(100.0 \%)$ & $15(93.8 \%)$ \\
\hline & Health Centre & $1(100.0 \%)$ & $0(0.0 \%)$ & $0(0.0 \%)$ & $2(100.0 \%)$ & $3(100.0 \%)$ \\
\hline \multirow{2}{*}{ Gender } & Females & $8(66.7 \%)$ & $4(57.1 \%)$ & $6(100 \%)$ & $7(70 \%)$ & $25(71.4 \%)$ \\
\hline & Males & $4(33.3 \%)$ & $3(42.9 \%)$ & $0(0.0 \%)$ & $3(30.0 \%)$ & $10(28.6 \%)$ \\
\hline \multirow{3}{*}{$\begin{array}{l}\text { Years } \\
\text { practicing }\end{array}$} & $1-5$ Years & $3(25.0 \%)$ & $0(0.0 \%)$ & $0(0.0 \%)$ & $3(30 \%)$ & $6((17.1 \%)$ \\
\hline & 6 - 10 Years & $6(50 \%)$ & $4(57.1 \%)$ & $5(83.3 \%)$ & $4(40.0 \%)$ & $19(54.3 \%)$ \\
\hline & More than 11 Years & $3(25 \%)$ & $3(42.9 \%)$ & $1(16.7 \%)$ & $3(30.0 \%)$ & $10(28.6 \%)$ \\
\hline \multirow{4}{*}{$\begin{array}{l}\text { Rank of Health } \\
\text { providers }\end{array}$} & Enrolled Nurse & $4(33.3 \%)$ & $3(42.9 \%)$ & $5(83.3 \%)$ & $8(80.0 \%)$ & $20(57.1 \%)$ \\
\hline & Enrolled Nurse Midwife & $3(25.0 \%)$ & $0(0.0 \%)$ & $0(0.0 \%)$ & $0(0.0 \%)$ & $3(8.6 \%)$ \\
\hline & Registered Nurse & $5(41.7 \%)$ & $4(57.1 \%)$ & $1(16.7 \%)$ & $1(10.0 \%)$ & $11(31.4 \%)$ \\
\hline & Registered Nurse Midwife & $0(0.0 \%)$ & $0(0.0 \%)$ & $0(0.0 \%)$ & $1(10.0 \%)$ & $1(2.9 \%)$ \\
\hline
\end{tabular}

The findings on the nurses' visits to schools and the provision of health education in the region indicated low school visits and provision of health education to school learners in Otjozondjupa region, as demonstrated by Figure 1.

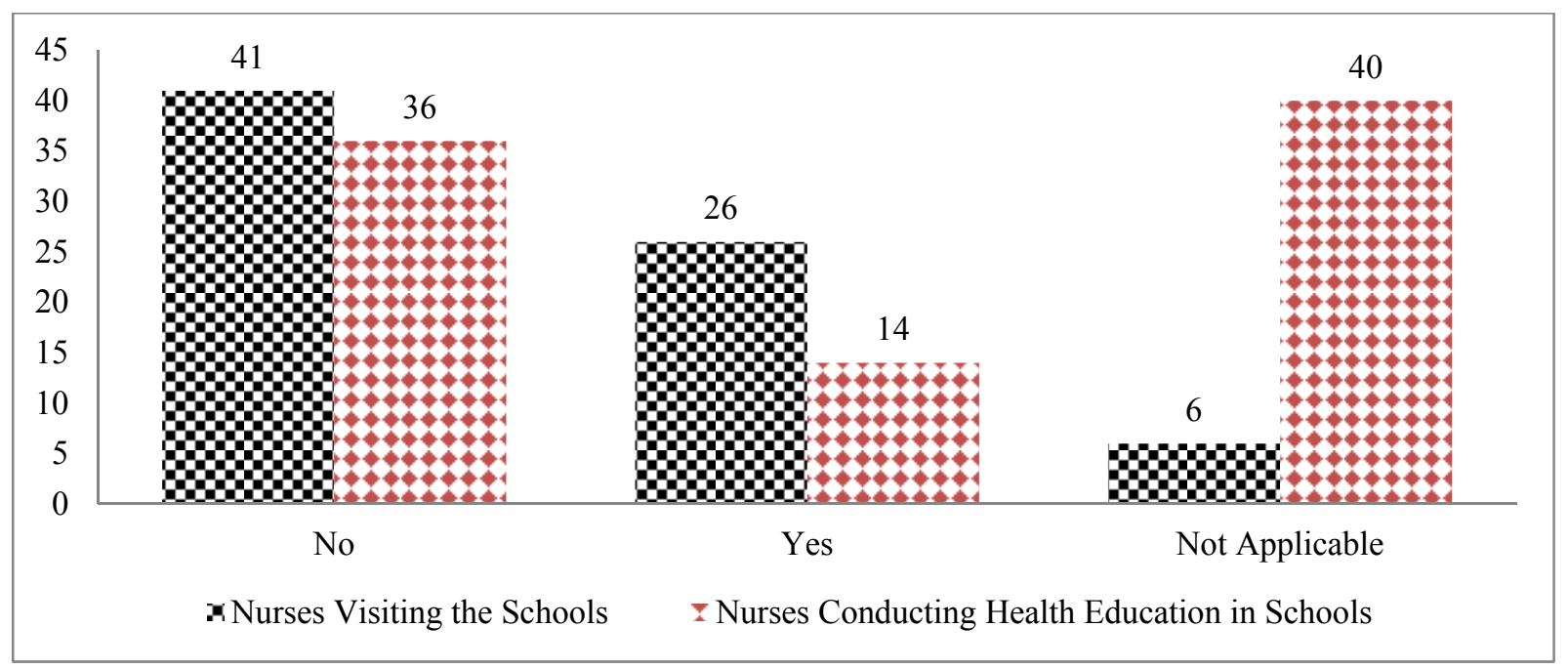

Figure 1. Nurses' visit to schools and conducting of health education: Black colour represents Enrolled Nurse-midwives, while the red colour represents the Registered Nurse-Midwives

\subsection{Service Providers' Technical Competencies}

The findings indicated that $75 \%$ of the registered nurse-midwives and only $30 \%$ of the enrolled nurse-midwives who participated in the study were trained in adolescent sexual and reproductive health. However, $100 \%$ of the registered nurse-midwives whilst $75 \%$ of the enrolled nurse-midwives indicated that they conducted school outreach programmes. 
Table 3. Health Providers' Qualifications and Key Adolescent Health Attributes

\begin{tabular}{llcl}
\hline \multirow{2}{*}{ Variable } & & \multicolumn{2}{c}{ Technical competencies of per categories of nurse providers for the AFHS } \\
\cline { 3 - 4 } & & Enrolled Nurse-Midwife [ENM] & Registered Nurse and Midwife [RNM] \\
\hline Trained in adolescent sexual & No & $16 / 23(70 \%)$ & $3 / 12(25 \%)$ \\
and reproductive health issues & Yes & $7 / 23(30 \%)$ & $9 / 12(75 \%)$ \\
You/ your colleagues conduct & No & $3 / 23(13 \%)$ & $3 / 12(25 \%)$ \\
outreach to local schools & Yes & $20 / 23(87.0 \%)$ & $9 / 12(75.0 \%)$ \\
Do you give health education* & No & $1 / 19(5 \%)$ & $0(0 \%)$ \\
& Yes & $18 / 19(95 \%)$ & $8 / 8(100 \%)$ \\
\hline
\end{tabular}

Table 4. Health Services Providers' years of practicing and key Adolescent health attributes

\begin{tabular}{|c|c|c|c|c|c|c|c|}
\hline \multirow[t]{3}{*}{ Variable } & & \multicolumn{6}{|c|}{ YEARS OF EXPERIENCE } \\
\hline & & \multicolumn{3}{|c|}{ Registered Nurse Midwives } & \multicolumn{3}{|c|}{ Enrolled Nurse Midwives } \\
\hline & & $1-5$ & $6-10$ & $11-20+$ & $1-5$ & $6-10$ & $11-20+$ \\
\hline \multirow[t]{2}{*}{$\begin{array}{l}\text { Trained in adolescent sexual and } \\
\text { reproductive health issues }\end{array}$} & YES & $\begin{array}{l}1 / 12 \\
(8 \%)\end{array}$ & $\begin{array}{l}6 / 12 \\
(50 \%)\end{array}$ & $\begin{array}{l}2 / 12 \\
(17 \%)\end{array}$ & $\begin{array}{l}4 / 23 \\
(17 \%)\end{array}$ & $\begin{array}{l}3 / 23 \\
(13 \%)\end{array}$ & $\begin{array}{l}0 / 23 \\
(0 \%)\end{array}$ \\
\hline & NO & $\begin{array}{l}2 / 23 \\
(9 \%)\end{array}$ & $\begin{array}{l}1 / 23 \\
(4 \%)\end{array}$ & $\begin{array}{l}0 / 23 \\
(0 \%)\end{array}$ & $\begin{array}{l}2 / 23 \\
(9 \%)\end{array}$ & $\begin{array}{l}6 / 23 \\
(26 \%)\end{array}$ & $\begin{array}{l}8 / 23 \\
(35 \%)\end{array}$ \\
\hline \multirow[t]{2}{*}{$\begin{array}{l}\text { You/ your colleagues conduct outreach } \\
\text { to local schools }\end{array}$} & YES & $\begin{array}{l}3 / 12 \\
(25 \%)\end{array}$ & $\begin{array}{l}4 / 12 \\
(33 \%)\end{array}$ & $\begin{array}{l}2 / 12 \\
(17 \%)\end{array}$ & $\begin{array}{l}11 / 23 \\
(47 \%)\end{array}$ & $\begin{array}{l}7 / 23 \\
(30 \%)\end{array}$ & $\begin{array}{l}2 / 23 \\
(9 \%)\end{array}$ \\
\hline & NO & $\begin{array}{l}3 / 12 \\
(25 \%)\end{array}$ & $\begin{array}{l}0 / 12 \\
(0 \%)\end{array}$ & $\begin{array}{l}0 / 12 \\
(0 \%)\end{array}$ & $\begin{array}{l}0 / 23 \\
(0 \%)\end{array}$ & $\begin{array}{l}3 / 23 \\
(13 \%)\end{array}$ & $\begin{array}{l}0 / 23 \\
(0 \%)\end{array}$ \\
\hline \multirow[t]{2}{*}{$\begin{array}{l}\text { AFHS outreach to schools, do you give } \\
\text { health education* }\end{array}$} & YES & $\begin{array}{l}1 / 8 \\
(13 \%)\end{array}$ & $\begin{array}{l}2 / 8 \\
(25 \%)\end{array}$ & $\begin{array}{l}5 / 8 \\
(63 \%)\end{array}$ & $\begin{array}{l}6 / 19 \\
(32 \%)\end{array}$ & $\begin{array}{l}1 / 19 \\
(5 \%)\end{array}$ & $\begin{array}{l}11 / 19 \\
(58 \%)\end{array}$ \\
\hline & NO & $0 / 8(0 \%)$ & $0 / 8(0 \%)$ & $0 / 8(0 \%)$ & $\begin{array}{l}0 / 19 \\
(0 \%)\end{array}$ & $\begin{array}{l}1 / 19 \\
(5 \%)\end{array}$ & $\begin{array}{l}0 / 19 \\
(0 \%)\end{array}$ \\
\hline
\end{tabular}

The adolescent friendly health environment was the second component of the AFHS that was assessed, findings of which are displayed in the next session.

\subsection{Adolescent Friendly Health Environment}

Out of an estimated sample of 19 health facilities ( 16 clinics and 3 health centers), one health facility (clinic) could not participate in the study as it was closed at the time of the study.

There were more clinics $(83.3 \% ; n=15)$ than health centres $(16.7 \% ; n=3)$. Proportional representations of health facilities are illustrated in Table 2.

Table 5. Type and proportions of health facility that participated in study by district

\begin{tabular}{llll}
\hline & \multicolumn{3}{l}{ Facility } \\
\hline \multirow{3}{*}{ District } & Crootfontein & $5(27.8 \%)$ & Health Centre \\
& Okahandja & $2(11.1 \%)$ & $1(5.6 \%)$ \\
& Okakarara & $6(33.3 \%)$ & \\
\hline Total & Otjiwarongo & $2(11.1 \%)$ & $2(11.1 \%)$ \\
\hline
\end{tabular}


Table 6 displays findings on evidences of adolescent friendly health services in health facilities.

Table 6. Adolescent Friendly Health Environment Attributes $(n=18)$

\begin{tabular}{llll}
\hline Adolescent Friendly Health Environment Attributes & Response & Frequency & Percent \\
\hline Is there any room or space designated for adolescent at the facility & No & 17 & $94.4 \%$ \\
& Yes & 1 & $5.6 \% \%$ \\
Room location accessible for adolescent accessible & Yes & 1 & $5.6 \%$ \\
& No & 17 & 94.4 \\
Are the consulting rooms clearly marked with numbers instead of labeling & No & 15 & $83.3 \%$ \\
the services which are being given? & Yes & 3 & $16.7 \%$ \\
Are there any adolescent friendly IEC materials on health issues displayed in & Yes & 18 & $100.0 \%$ \\
the facility? & No & 17 & $94.4 \%$ \\
Is information on where to get condoms displayed in the facility? & Yes & 1 & $5.6 \%$ \\
Are the condoms accessible in the health facility? & Yes & 18 & $100.0 \%$ \\
Are there any records of the activities of the Health Facility Committee in the & No & 18 & $100.0 \%$ \\
facility? & No & 11 & $61.1 \%$ \\
Are there any records of school visits kept in the health facility? & Yes & 7 & $38.9 \%$ \\
\hline
\end{tabular}

\subsection{Reliability and Validity}

Reliability of the data was ensured by pilot testing of the questionnaire on 2 registered nurse midwives and 3 enrolled nurse midwives who were of similar context to that of the participants in the actual study (De Vos et al., 2011) but did not participate in the actual study.

Validity of the data was ensured by the sample achievement of $92 \%(n=35)$ of all nurses (registered nurses and enrolled nurse) and of $94.7 \%(\mathrm{n}=18)$ of all 19 health facilities that implement the Adolescent Friendly Health Services in Otjozondjupa region at the time of the study. Inclusions in the questionnaire and the checklist of all the information that is essential to assess the two components ensured content validity. Triangulation of the data from the two sources also ensured the validity of the data as the different source provided information of different perspective (Brink, 2012; De Vos et. al, 2011) about the implementation of the AFHS standards at the health facilities. However, an extensive study of a representative sample for each of all 14 regions would ensure added validity of the data. The next section presents the discussion and conclusions and outlines the recommendations pertaining to the findings.

\section{Discussion}

The purpose of the study was to assess the implementation by nurses of the adolescent friendly health services providers and the adolescent friendly health services environment components of the AFHS standards at the health care facilities in the Otjozondjupa region of Namibia. Evidences for the implementation of these two components may be inferred from the attributes of nurses who provide services to the adolescent and of the health care facilities where such services are being provided. The findings pertaining to the component on adolescent friendly health services provider are discussed first.

\subsection{Adolescent Friendly Health Service Providers}

In addition to their demographic characteristics, services providers' technical competencies as indicated by their qualifications, years of experiences, dispositions of attributes that can facilitate the provision of adolescent friendly health services and whether they carry out the activities of the AFHS standards were assessed. The findings are discussed in the succeeding respective sessions.

\subsubsection{Training in Sexuality and Reproductive Health}

Well-trained, sensitive services providers are often considered to represent the most important elements of a 
truthfully youth-friendly service. In Namibia, the component of the adolescent friendly health services provider is implemented through the health services at health care facilities, mainly by nurses. Therefore, for a successful implementation of the AFHS standards at the health care facilities, the nurses' technical competencies, attitudes and subsequent actions should affirm likewise.

The study showed that $25 \%$ of the registered nurse-midwives, and $70 \%$ of the enrolled nurse- midwives who participated in the study were not formally trained in adolescent sexual and reproductive health issues. This implies that on average, $48 \%$ of all the study participants were not formally trained in adolescent sexual and reproductive health issues. Except for $13 \%$ of the enrolled nurse-midwives who were not formerly trained in adolescent sexual and reproductive health issues, none of the registered nurse-midwives who were not formerly trained in adolescent sexual and reproductive health issues have received any orientation on providing adolescent sexual and reproductive health services. However, this revelation is in contrary to the reality that service providers should be knowledgeable in order for them to demonstrate the understanding of principles that are fundamental to adolescent sexual and reproductive health rights and equally to display positive attitude towards young people's sexuality. These dispositions increase the utilization of the service by the intended recipients (WHO, 2006; The High Impact Practice in Family Planning, 2015). Therefore, providers' knowledge, skills, and right attitudes based on both formal and on-going training and support is due for nurses who are expected to provide adolescent friendly health services.

Furthermore, the evidence from this study indicated that $75 \%$ of the registered nurse-midwives, and $87 \%$ of the enrolled nurse- midwives conducted adolescent health outreach activities at local schools. Out of these, all (100\%) of the registered nurse-midwives, and $95 \%$ of the enrolled nurse-midwives reported to had conducted health education during their visit to local schools. Whereas the study observed that health care providers in Otjozondjupa region do implement school outreach programme, the provision of the Adolescent Friendly Health Services appears not to be inclusive of the school outreach programme. Inclusiveness of the adolescent friendly health services are to be substantiated by the degree of the utilization of the AFHS by the adolescents. However, the expected is nullified by the report on the component about Adolescent Active Participation, which revealed low awareness of the AFHS and risky sexual behaviours among the adolescent participants of the same study (Muyenga, Amakali \& Wilkinson, 2017).

\subsubsection{Technical Competencies of the Nurse Services Providers}

The findings of the study indicated that the majority (68\%) of the enrolled nurse-midwives who conducted school outreach health services has working experiences of between 6-10 years, however never conducted health education during schools outreach services. A lack of provision of health education by enrolled nurse-midwives can be related to a lack of training about issues of sexuality and reproductive health among this category of nurses as reflected in table 3 of the findings. Given a lack of training in adolescent related health issues and the subsequent low degree of health education to school learners by health care providers, the findings are suggestive that the interventions of the school outreach programme in the region of study are still focused on a traditional school health service and not necessary on health promotion which is inclusive of the provision of adolescent friendly health services.

\subsubsection{Provision of AFHS by the Study Participants}

All most all the registered nurse-midwives as well as the majority of the enrolled nurse-midwives who responded to the question on the provision of adolescent friendly health services to school learners indicated that they conducted health education sessions to local schools during their outreach visits to the schools. However, the study noted that as much as health care providers in the region claim to provide adolescent friendly health, the majority of the respondents who were pro-health education to the adolescents at school were the enrolled nurses, yet the majority of whom were not trained in sexual and reproductive issues as implied in table 3. Training in adolescent friendly health services is a pre-requisite for successful implementation of the AFHS initiatives. Therefore, all the nurses who partake in service delivery should acquire attributes that convince that they have necessary competencies to deliver the services. Without sufficient training and orientation in AFHS, nurses would not be able to implement the AFHS effectively.

\subsection{Adolescent Friendly Environment}

The findings showed that all the participating health facilities had adolescent friendly Information Education and Communication (IEC) materials displayed. However, only 5.6\% $(\mathrm{n}=1)$ of the health care facilities had the information on the accessibility of condoms by the clients. Likewise, the findings revealed that $90 \%$ of the health facilities had no room or space designated for adolescent related health services. For the only $5.6 \%(n=1)$ of the 
health care facilities which had a space designated for adolescent health services, the type of the services the room is designated to was not clearly indicated.

A lack of adolescent friendly environment at the health facilities turns off the adolescents, thus resulting in low utilization of the adolescent health services (WHO, 2012). The findings therefore indicated a correlation of lack of adolescent friendly environment and lack of knowledge about the availability of the adolescent friendly health services initiative and risky sexual behaviors among the adolescent participants of the same study (Muyenga, Amakali \& Wilkinson, 2017).

Successful implementation of the adolescent friendly services at the health care facilities requires an environment characterized of accessibility of services through location-the wait in a place where clients are ensured of privacy and confidentiality while having access to educational and information materials. The services should also be offered at the time convenient for the clients (WHO, 2012).

\section{Conclusions}

The study revealed that although the guidelines for the implementation of AFHS are available at the health care facilities, the components on Adolescent Friendly Health Care providers and Adolescent Friendly Health Environment are not being effectively implemented by nurses in Otjozondjupa region. This is evidenced by lack of relevant training among a significant number of nurses as providers, but only very few of them had received some orientation on adolescent reproductive and sexual health issues and by the low provision of health education to adolescents at schools.

The study further concluded that the health facilities were not adolescent friendly as the majority of them had no room or space designated for adolescent related health services, coupled with limited information on adolescent health as well as lack of documented evidences of the activities of the Health Facility Committee in the health facilities.

In conclusion, the result of the study inversely answered the research question whether nurses at the health facilities in Otjozondjupa region implement the Adolescent Friendly Health Services guidelines effectively, and whether health care facilities displays display adolescent friendly environment.

\section{Recommendations}

Based on the conclusions, the recommendations were made for the improvement of the implementation of the adolescent friendly health services provider and adolescent friendly health environment components of the AFHS initiative. With regard to the first component, the study recommended close monitoring and reinforcement of application of the guidelines for Adolescents Friendly Health Services by nurse at health care facility, in-services training for nurses who are to implement the AFHS initiatives on principles of the AHFS initiatives and spelling out of giving health education to adolescents as part of the school outreach package. By the implications, close monitoring is required for a successful implementation of the standard for Adolescent Friendly Health Services in the region.

The study further recommended the inclusion of a detailed module on Adolescent Friendly Health Services in the curriculum for local training of all categories of nurses. This would ensure a comprehensive capacity for graduate nurses, who then would be able to provide health care of diverse perspectives.

Moreover, the study recommended separation by health care providers of their personal values from their professional duties. Although every individual health care provider has the right to his or her values about adolescent sexual behaviour, providers must, at times, separate their personal values from their professional duties and offer quality reproductive health care to youth without reservation. Disposition of services based on a sense of professional responsibility would in return ensure the facilitation of environment that is adolescent friendly.

\section{Delimitation and Limitations}

The study was delimited to nurses and health facilities in Otjozondjupa region. Therefore, the interpretations of the findings cannot be generalized to other regions which may have different contexts of services deliverance. The quality of the data on the component of adolescent friendly health services provider might have been minimized since the data was collected through self-administered questionnaires in contrast to the data that would have been collected through face-to-face interviews.

\section{Acknowledgements}

Respective acknowledgements are accorded to the Ministry of Health and Social Services and the district nurses for granting the prime researcher permission to collect the data at the health care facilities. All the study 
participants at all health facilities are sincere acknowledged for their time, cooperation and provision of information which are important for the improvement of deliverance of the AFHS.

\section{Competing Interests Statement}

The authors declare that there are no competing or potential conflicts of interest.

\section{References}

Babbie, E., \& Mouton, J. (2010). The Practice of Social Research. Cape Town: Oxford University Press.

Brink, H., van Rensburg, G., \& van der Walt, C. (2012). Fundamentals of Research Methodology for Health Care Professionals (2nd ed.). Cape Town: Juta \& Co. (Pty) Ltd.

De Vos, A., Strydom, H., Fouche, C., \& Delport, C. (2011). Research at Grass Roots: For the Social Sciences and human service professions (4th ed.). Pretoria: Van Schaik.

High-Impact Practices in Family Planning (HIPs). (2015). Adolescent-friendly Contraceptive Services: Mainstreaming Adolescent-friendly Elements into Existing Contraceptive Services. Washington (DC): USAID.

Joubert, G., \& Ehrlich, R. (2014). Epidemiology: A Research manual for South Africa (2nd ed.). South-Africa: Oxford University Press.

McIntyre, P. (2003). Adolescent friendly health services: An agenda for Change. Geneva: WHO.

Ministry of Health and Social Services Otjozondjupa Regional Office. (2014). Health.

Ministry of Health and Social Services. (2011). Namibia, National Standards for Adolescent Friendly Health Services MoHSS: Windhoek.

Ministry of Health and Social Services. (2012). Report on the 2012 National HIV Sentinel Survey Namibia: Windhoek.

Ministry of Health and Social Services. (2008). Namibia Demographic and Health Survey.

Parahoo, K. (2006). Nursing Research: Principle, Process and Issues ( $6^{\text {th }}$ ed.) New York: Palgrave MacMillan.

Pathfinder International. (2002). Clinic Assessment of Youth Friendly Services: A Tool for Assessing and Improving Reproductive Health Services for Youth. Watertown.

Streubert-Speziale, H. J., \& Carpenter, D. R. (2007). Qualitative research in Nursing: Advancing the humanistic imperative (4th ed.) Philadelphia: Lippincot Williams \& Wilkins.

United Nations Children's Emergency Fund. (2006). Guidelines for Adaptation of the WHO Orientation Programme on Adolescent Health Care Providers in Europe and Central Asia. Geneva: United Nation (UN).

World Health Organisation. (2006). Defining sexual health Report of a technical consultation on sexual health. Geneva: WHO.

World Health Organization. (2012). Making Health Services Adolescent Friendly: Developing National Quality Standards for Adolescent Friendly Health Services. Geneva: WHO ISBN 9789241503595.

World Health Organization. (2012). Making health services adolescent Developing national quality standards for adolescent friendly health services Department of maternal and child health. Geneva: WHO.

World Health Organization. (2008). Department of Child and Adolescent Health and Development: Orientation Programme on Adolescent Health for Health-Care Providers, Facilitator's Guide. Geneva: United Nation.

\section{Copyrights}

Copyright for this article is retained by the author(s), with first publication rights granted to the journal.

This is an open-access article distributed under the terms and conditions of the Creative Commons Attribution license (http://creativecommons.org/licenses/by/4.0/). 